\title{
ESTIMATIVA NÃO DESTRUTIVA DO TEOR FOLIAR DE NITROGÊNIO EM CACAUEIRO UTILIZANDO CLOROFILÔMETRO ${ }^{1}$
}

\author{
PAULO ALFREDO DE SANTANA DANTAS², JOSÉ OLIMPIO DE SOUZA JÚNIOR ${ }^{3}$, \\ FÁBIO PINTO GOMES ${ }^{4}$, DANIEL ORNELAS RIBEIRO ${ }^{5}$
}

RESUMO-A substituição do método tradicional de avaliação do teor de nitrogênio (N) na planta pelo uso do medidor portátil de clorofilas do tipo SPAD é promissora por se tratar de um aparelho portátil que estabelece um índice de modo não destrutivo, instantâneo e com menor custo. Objetivou-se determinar a capacidade deste aparelho em estimar o teor foliar de $\mathrm{N}$ do cacaueiro. A área de abrangência deste estudo envolve as zonas climáticas úmida e úmida a subúmida da região cacaueira da Bahia. Foram selecionadas dez propriedades rurais, em cada zona, com lavoura em sistema agrossilvicultural, que tiveram a área renovada por enxertia de broto basal com clones tolerantes à vassoura-de-bruxa. Em cada propriedade, quatro plantas com idade superior a quatro anos foram selecionadas em condições edáficas e topográficas distintas. Foram coletadas oito folhas sadias por planta e, em cada uma delas, foram feitas seis leituras do índice SPAD. Além disso, determinaram-se o teor e o conteúdo de $\mathrm{N}$ na folha, a área foliar (AF) e a massa foliar específica (MFE). $\mathrm{O}$ índice SPAD correlacionou se, significativa e positivamente com o teor foliar de $\mathrm{N}(\mathrm{r}=0,74)$, com a AF $(\mathrm{r}=0,62)$ e negativamente com a MFE $(\mathrm{r}=-0,57)$. Não houve correlação entre o conteúdo de $\mathrm{N}$ e o índice SPAD. O modelo de regressão linear simples para a predição do teor de $\mathrm{N}$, a partir do índice SPAD, sem a distinção dos ambientes, foi o mais apropriado.

Termos para indexação: ecofisiologia, Theobroma cacao, diagnóstico nutricional.

\section{NON DESTRUCTIVE ESTIMATION OF FOLIAR NITROGEN IN CACAO TREE USING CHLOROPHYLL METER}

\begin{abstract}
The replacement of the traditional method for evaluating the nitrogen $(\mathrm{N})$ in the plant by the use of portable chlorophyll meter SPAD is promising because it is a portable device that provides a nondestructive, instant and low cost index.This study aimed to determine the ability of this device in estimating leaf $\mathrm{N}$ content of cocoa. The area covered by this study involves the wet and humid climate zones of the sub humid cocoa region of Bahia. Were selected ten farms, in each area, with crops in agroforestry system and that the area had renewed by grafting of basal shoot with clones tolerant to witches' broom. In each farm, four plants over the age of four years were selected in different topographic and soil conditions. It was collected eight healthy leaves per plant and in each, was made six SPAD readings of the index. Furthermore, were determined the $\mathrm{N}$ content, $\mathrm{N}$ content, leaf area (LA) and specific leaf mass (SLM). The SPAD index was significantly positively correlated with leaf $\mathrm{N}$ content $(\mathrm{r}=0.74)$, with $\mathrm{AF}(\mathrm{r}=0.62)$ and negatively with the MFE $(r=-0.57)$. There was no correlation between $N$ content and SPAD index. There was no correlation between $\mathrm{N}$ content and SPAD index. The simple linear regression model to predict the $\mathrm{N}$ content from SPAD index, without distinction of environments was more appropriate.
\end{abstract}

Index terms: ecophysiology,Theobroma cacao, nutritional diagnosis.

\footnotetext{
${ }^{1}$ (Trabalho 178-11). Recebido em: 06-06-2011. Aceito para publicação em: 23-08-2012. Parte da Dissertação de Mestrado do primeiro autor apresentado ao Programa de Pós-Graduação em Produção Vegetal, Universidade Estadual de Santa Cruz - UESC, Rod. Ilhéus-Itabuna, km 16, CEP 44662-000 Ilhéus-BA.

${ }^{2}$ Eng $^{\circ}$ Agrônomo, Mestre em Produção Vegetal, UESC. E-mail: padantas@gmail.com

3Professor do Departamento de Ciências Agrárias e Ambientais, UESC. E-mail: olimpio@uesc.br

${ }^{4}$ Professor do Departamento de Ciências Biológicas, UESC. E-mail: gomes@uesc.br

${ }^{5}$ Eng ${ }^{\circ}$ Agrônomo, Mestre em Produção Vegetal, UESC. E-mail: ornelasrib@hotmail.com
} 


\section{INTRODUÇÃO}

O Brasil e a Malásia, dentre os países produtores de cacau, são os que vêm usando com maior intensidade sistemas de produção com tecnologia moderna (CHEPOTE et al., 2005), o que pode explicar o aumento da produção no Brasil. Em 2010, a produção brasileira somou 199.790 t de amêndoas secas, um aumento de 29,8\% sobre as $153.936 \mathrm{t}$ em 2009 e o melhor desempenho desde 1996 (SEAGRI, 2011). No Brasil, a principal região produtora de cacau é o sul da Bahia, responsável por 72,8 \% da produção nacional (MANDARINO; GOMES, 2009).

As respostas ao emprego de corretivos e fertilizantes são evidentes nas culturas, destacadamente com a adubação nitrogenada, pois a capacidade fotossintética das plantas é grandemente dependente da disponibilidade de nitrogênio (N). Este macronutriente é necessário para garantir a integridade estrutural e funcional da clorofila e das proteínas (MAJEROWICZ, 2004). Para a recomendação de fertilizantes nitrogenados, a análise foliar tem sido apontada como uma boa ferramenta. Porém, a depender da região e de sua disponibilidade de laboratórios, o intervalo entre a coleta da amostra e a entrega dos resultados pode ser extenso ao ponto de prejudicar a produtividade da cultura.

A quantificação da matéria orgânica do solo também pode servir para a recomendação de adubação nitrogenada no Brasil, mas somente nos estados do sul, de clima temperado, onde existe correlação entre esta característica do solo e o $\mathrm{N}$ absorvido pelas culturas (GIANELLO et al., 2000). A adubação nitrogenada para a cacauicultura não tem sido eficiente, pois há escassez de pesquisas sobre este tema. Atualmente, na ausência da análise foliar, a dose recomendada para a lavoura do sul da Bahia é fixa em $60 \mathrm{~kg} \mathrm{ha}^{-1}$ de N (CHEPOTE et al., 2005).

A substituição dos métodos tradicionais de avaliação da disponibilidade de $\mathrm{N}$ para as plantas, pelo uso do medidor portátil de clorofilas do tipo SPAD (Soil and Plant Analysis Development), é promissor por se tratar de um aparelho portátil que estabelece um índice de modo não destrutivo, instantâneo (GODOY et al., 2008) e com menor custo (ARGENTA et al., 2001). O valor dado pelo SPAD é obtido pela transmitância de luz através da folha, no comprimento de onda com pico em 650 nm (região de alta absorbância pelas moléculas de clorofila) e com pico em 940 nm (baixa absorbância), servindo como fator de correção para o teor de água ou espessura da folha (ARGENTA et al., 2001; GODOY et al., 2003). Em síntese, o aparelho mede o índice de esverdeamento foliar que se correlaciona ao teor de clorofila. Como até $70 \%$ do nitrogênio em células do mesofilo, pode estar localizado no cloroplasto (REIS et al., 2006) e, como existe estreita correlação entre os teores de $\mathrm{N}$ e de clorofilas no tecido foliar (EVANS, 1989), correlações entre o índice SPAD e o nitrogênio foliar são esperadas. Tais correlações foram observadas em milho (ARGENTA et al., 2001), mamão (TORRES NETTO et al., 2002), pimentão (GODOY et al., 2003), Acer saccharum Marsh (VAN DEN BERG; PERKINS, 2004), café (TORRES NETTO et al., 2005; GODOY et al., 2008) e gramíneas (LAVRES JÚNIOR; MONTEIRO, 2006; COSTA et al., 2008).

As relações matemáticas entre o índice SPAD e o teor de nitrogênio variam inter e intraespécies (VAN DEN BERG; PERKINS, 2004). O índice pode variar durante as fases de desenvolvimento da planta (GODOY et al., 2008) e com as variações ambientais a que estão submetidas (VAN DEN BERG; PERKINS, 2004).

O objetivo deste estudo foi determinar a capacidade do medidor de clorofila SPAD-502 em estimar o teor de nitrogênio foliar do cacaueiro (Theobroma cacao) numa larga amplitude de ambientes dentro da região cacaueira da Bahia.

\section{MATERIAL E MÉTODOS}

Foram selecionadas vinte propriedades rurais no sul da Bahia, que possuem lavoura cacaueira em sistema agrossilvicultural sem irrigação e que foram submetidas aos seguintes procedimentos técnicos: renovação da área pela técnica de enxertia de broto basal com clones tolerantes à vassoura-de-bruxa (Moniliophthora perniciosa); aumento da densidade para uma média de 900 a 1.000 plantas ha-1 ${ }^{-1}$ remoção de espécies arbóreas consideradas indesejáveis por sombrear excessivamente a lavoura; e manejo da sombra através da poda de árvores remanescentes (MANDARINO; GOMES, 2009).

No sul da Bahia, as precipitações e a umidade relativa do ar diminuem no sentido leste-oeste (do oceano Atlântico ao interior do continente). A umidade relativa da região varia de 76,3 a 84,2\% (NACIF, 2000). A área de abrangência do estudo envolve a zona úmida e úmida a subúmida da região. A zona úmida não possui estação seca definida e enquadra-se em sete tipos climáticos, segundo Thornthwaite: $\mathrm{B} 4 \mathrm{r}$ A', B3r A', B2r A', B2r B', B1r A', B1r' A' e B1w A'. A zona úmida a subúmida possui um a dois meses de seca e enquadra-se em quatro tipos climáticos: C2d A', C2d' A', C2d B' e C2w A' (SEI, 2007). Na Tabela 1 , as zonas envolvidas no estudo são caracterizadas quanto ao clima. 
Dentre as propriedades rurais selecionadas, dez estão em zona úmida e dez em zona úmida a subúmida (doravante denominada apenas como semiúmida). Na Tabela 2, estão relacionados os municípios e o número de propriedades rurais selecionadas a eles pertencentes.

Na zona úmida, em 60\% das propriedades rurais, foi aplicado adubo nitrogenado entre setembro e novembro de 2009, e $40 \%$ não foram adubadas. Na zona semiúmida, 20\% foram adubadas em março de 2009, 50\% foram adubadas entre setembro e novembro de 2009 e 30\% não foram adubadas.

As plantas selecionadas para o presente trabalho são clones PH16. Este material genético é adaptado às zonas úmida e semiúmida, tem produtividade média de 973 g de amêndoas secas por planta a partir do quarto ano, é autocompatível e tolerante à Moniliophthora perniciosa (MANDARINO; GOMES, 2009).

Em cada propriedade, quatro plantas com idade superior a quatro anos foram selecionadas em situações edáficas e topográficas distintas, buscando-se, assim, alcançar a maior variabilidade de solo possível. Espera-se, com a máxima variação de tipos de solo e consequente variação de disponibilidade de nutrientes, saber se o método de avaliação se correlaciona ao estado nutricional das plantas na mais ampla área possível, por motivos práticos - padronização do método (CANTARUTTI et al., 2007).

Foram coletadas oito folhas sadias por planta - a terceira a partir do ápice de um ramo recém-amadurecido sem lançamentos, no período do verão (SANTANA; IGUE, 1979; CHEPOTE et al., 2005), época de menor flutuação estacional do ano (CANTARUTTI et al., 2007), nos meses de janeiro e fevereiro de 2010. Em cada folha destacada da planta, foram feitas imediatamente seis leituras do índice SPAD com aparelho Chlorophyll Meter SPAD-502 da Minolta - três leituras de cada lado da nervura central no terço médio do limbo, na parte adaxial.

As leituras foram realizadas entre $9 \mathrm{~h}$ e $10 \mathrm{~h} 30$ horas, com o operador utilizando seu corpo para evitar a incidência direta da radiação sobre a folha, como sugerido por Godoy et al. (2008). Antes da realização das leituras, o aparelho foi calibrado com o verificador de leitura, de acordo com as recomendações do manual de instruções do fabricante. Os pontos amostrados por folha estavam a 6,0 $\mathrm{mm}$ da margem do limbo, distância fixada pelo regulador de profundidade do aparelho.

As folhas coletadas foram acondicionadas em sacos de papel e levadas ao laboratório da Universidade Estadual de Santa Cruz, onde foram analisadas. A área foliar (AF) foi medida com medidor de ban- cada LI-3100C. O material foi seco em estufa com circulação forçada de ar, à temperatura de $65^{\circ} \mathrm{C}$, até atingir peso constante. As amostras foram pesadas, moídas e o teor de $\mathrm{N}$ foi determinado, após digestão sulfúrica, por destilação-titulação de acordo com Embrapa (2009). A massa foliar específica (MFE) foi obtida pela razão entre a massa seca e a AF, e foi utilizada como indicativo da espessura da folha (GODOY et al., 2008). O conteúdo de $\mathrm{N}$ foi obtido pela multiplicação do teor de $\mathrm{N}$ pela massa média das folhas da planta.

As médias das variáveis analisadas foram submetidas à análise estatística exploratória, correlação linear simples de Pearson (utilizando o teste t para a verificação da significância) e regressão, sendo selecionado o modelo que apresentasse os coeficientes significativos a até $10 \%$, pelo teste $\mathrm{F}$, e maior coeficiente de determinação ajustado.

As equações de regressão das zonas climáticas foram submetidas ao teste de identidade de modelos, visando a avaliar diferenças entre os modelos para cada zona climática ou a possibilidade de utilizar apenas um modelo para as duas zonas. Esse teste consiste na redução da soma dos quadrados, permitindo verificar, estatisticamente, pelo teste de F, a significância da diferença entre o total das somas dos quadrados das regressões ajustadas para cada zona, isoladamente, e a soma do quadrado da regressão ajustada para o conjunto total dos dados (REGAZZI, 1996).

\section{RESULTADOS E DISCUSSÃO}

Na Tabela 3, são apresentadas as médias dos teores foliares de $\mathrm{N}$ nos dois ambientes, as quais variam de 14,0 $\mathrm{g} \mathrm{kg}^{-1}$ (plantas deficientes em N) a $31,0 \mathrm{~g} \mathrm{~kg}^{-1}$ (excesso de $\mathrm{N}$ ), com média de $21,3 \mathrm{~g} \mathrm{~kg}^{-}$ 1 , valor este que está dentro da faixa de suficiência para a cacauicultura sugerida por Malavolta (1987), corroborada por Cantarutti et al. (2007).

As folhas das plantas situadas na zona úmida apresentaram maior média (22,0 $\left.\mathrm{g} \mathrm{kg}^{-1}\right)$ e também maior variação; porém, nas duas zonas, a média encontra- se dentro da faixa de suficiência para a cultura (19,0 a 23,0 $\mathrm{g} \mathrm{kg}^{-1}$ ). Na zona úmida, 22,5 \% das plantas estão deficientes, $50 \%$ estão dentro da faixa de suficiência e $27,5 \%$ estão com excesso de $\mathrm{N}$. Na zona semiúmida, $22,5 \%$ estão deficientes, $60 \%$ dentro da faixa de suficiência e $17,5 \%$ com excesso de N.

Presume-se que, nos dois ambientes estudados, as variações de sombreamento sejam semelhantes, pois suas médias para MFE e AF estão próximas e com coeficientes de variação semelhantes 
(Tabela 3). Estudos mostram que a maioria das plantas da mesma espécie, cultivadas sob condições sombreadas, desenvolve folhas mais finas e maiores, proporcionando maior interceptação da luz disponível (MAJEROWICZ; PERES, 2004). As variações no teor de clorofila dentro de uma mesma espécie são correlatas às adaptações morfológicas ocorridas em resposta às variações de luminosidade no ambiente. Com o aumento da disponibilidade de luz, há menor necessidade de produção de clorofila, explicando a cor verde menos intensa de folhas de plantas da mesma espécie cultivadas a pleno sol (GODOY et al., 2008). As folhas de sombra apresentam maior teor de clorofila do que as folhas a pleno sol, porque este pigmento é constantemente sintetizado e destruído (foto-oxidação) em presença de luz (ENGEL; POGGIANI, 1991). O índice SPAD é influenciado por tais adaptações

O estudo de Engel e Poggiani (1991), sobre o desenvolvimento de mudas de quatro espécies florestais sob quatro níveis de sombreamento, confirma o observado no presente trabalho variações no esverdeamento das folhas dado pelo índice SPAD,correlacionado a variações na $\mathrm{AF}$ e MFE (Tabela 4). As variações de AF e MFE podem ser atribuídas a diferentes níveis de luminosidade, conforme Godoy et al. (2008) e Almeida e Valle (2007). O esverdeamento dado pelo teor de clorofila e, portanto, pelo índice SPAD, correlacionou-se positivamente à $\mathrm{AF}$ nos dois ambientes, tanto quando avaliados separadamente ou em conjunto (Tabela 4), indicando que o índice é influenciado pelas condições de sombreamento. Santiago et al. (2009) obtiveram resultados semelhantes ao testarem a correlação entre o índice SPAD e o comprimento foliar de quatro espécies de eucalipto em monocultivo e em consórcio.

O índice SPAD correlacionou- se significativa e positivamente à $\mathrm{AF}$ e negativamente à MFE (Tabela 4). Relação inversa entre MFE e índice SPAD também foi observada em seis espécies de árvores da Amazônia (MARENCO et al., 2009), em cafeeiros (GODOY et al., 2008) e em espécies de eucalipto consorciadas com Sesbania virgata (SANTIAGO et al., 2009). Este último autor verificou, inclusive, variação diretamente proporcional entre MFE das folhas de eucalipto e disponibilidade de luz (fluxo de fótons fotossintéticos) proporcionada pela poda da sesbânia. O índice SPAD diminui em folhas mais espessas porque estas têm menor transmitância devido ao efeito de desvio causado pela maior extensão de caminho óptico através da folha (MARENCO et al., 2009). Além disso, folhas de sol priorizam o investimento em bioquímica da fotossíntese, de modo que o $\mathrm{N}$ é preferencialmente alocado em enzimas cloroplastídicas, como redutase do nitrato, Rubisco, entre outras, em detrimento do sistema coletor de luz (clorofilas), preterido sob baixa irradiância (WANG et al., 2012).

Correlação significativa e positiva $(\mathrm{r}=0,74)$ também foi constatada entre o índice SPAD e o teor de $\mathrm{N}$ foliar (Tabela 4). Torres Netto et al. (2002) obtiveram elevada correlação $(r=0,97)$ entre teor foliar de $\mathrm{N}$ e leituras SPAD em mamão, o que thes permitiu indicar o SPAD como boa opção para a estimativa do teor foliar de N. Entretanto, os autores realizaram um ajuste não linear dos dados utilizando um modelo potencial modificado, o que não permite comparação fiel com os dados do presente estudo. Resultados semelhantes foram observados para outras espécies vegetais (ARGENTA et al., 2001; GODOY et al., 2003; VAN DEN BERG; PERKINS, 2004; TORRES NETTO et al., 2005; LAVRES JÚNIOR; MONTEIRO, 2006; GODOY et al., 2008; COSTA et al., 2008).

O conteúdo total de $\mathrm{N}$ nas folhas pouco se correlacionou ao índice SPAD: para a zona úmida, não houve correlação significativa e, para a zona semiúmida, houve correlação significativa, porém com coeficiente de correlação baixo (Tabela 4), ou seja, o índice de esverdeamento, dado pelo aparelho, correlaciona-se bem à quantidade relativa de $\mathrm{N}$ na folha (teor, $\mathrm{g} \mathrm{kg}^{-1}$ ), mas não com a quantidade total acumulada (conteúdo, mg por folha).

$\mathrm{O}$ modelo de regressão selecionado para a predição do teor de $\mathrm{N}$ pelo índice SPAD foi o linear (Figura 1). O teste de identidade de modelos de regressão não detectou diferenças entre as zonas úmida e semiúmida (Tabela 5), apesar de que essas regiões do sul da Bahia têm diferenças climáticas, especialmente com relação ao regime hídrico (Tabela 1). Diante disso, pode-se afirmar que os modelos para predição do teor de $\mathrm{N}$ em cada zona climática podem ser reduzidos a um só para as duas zonas. Van den Berg e Perkins (2004) analisaram folhas de Acer saccharum Marsh. em sub-bosque e em áreas abertas e constataram que o índice SPAD foi capaz de prever o teor de $\mathrm{N}$ foliar também por um modelo linear $\left(\mathrm{R}^{2}\right.$ $=0,64)$, independentemente da localização da planta. Em café, regressão linear mais bem ajustada $\left(\mathrm{R}^{2}=\right.$ 0,98 ) tem sido relatada em estudo sobre o efeito de doses de N (REIS et al., 2006), certamente porque, neste caso, as condições experimentais puderam ser mais controladas. Em outro estudo com café, onde as coletas foram feitas de forma semelhante às do presente estudo, a regressão linear mostrou valores de confiabilidade próximos ao apresentado aqui para cacau $\left(\mathrm{R}^{2}=0,69\right)$ (TORRES NETTO et al., 2005), 
apesar de os autores terem utilizado o teor de $\mathrm{N}$ expresso com base em área foliar. Neste estudo, a correlação entre o índice SPAD e o teor de $\mathrm{N}$ com base em AF $\left(\mathrm{mg} \mathrm{m}^{-2}\right)$ foi não significativo $(r=-0,19)$.

O teor de clorofilas e o esverdeamento foliar são afetados por inúmeros fatores, entre os quais o teor de $\mathrm{N}$, devido ao fato de que a maior parte do $\mathrm{N}$ foliar está associado às moléculas de clorofila (PETERSON et al., 1993). Entretanto, considerando que 50 a $70 \%$ do $\mathrm{N}$ total das folhas podem estar alocados em proteínas, como a redutase do nitrato, que estão associadas aos cloroplastos (REIS et al., 2006), observou-se que nem sempre menor índice SPAD significou menor teor de $\mathrm{N}$, o que explica, em parte, o valor modesto do coeficiente de determinação da regressão do teor foliar de $\mathrm{N}$ estimado pelo índice SPAD (Figura 1). Além disso, deve-se considerar que a variabilidade ambiental da lavoura cacaueira do sul da Bahia, e consequentemente deste estudo, é grande, pois foram avaliadas as duas regiões climáticas onde a lavoura é dominante e também porque se buscou diversidade de manejo e pedológica, já que foram amostrados 80 cacaueiros em 20 propriedades rurais, sendo que os quatro cacaueiros em cada propriedade estavam localizados em áreas distintas; ademais estes cacaueiros são cultivados em sistema agrossilvicultural, que é bastante heterogêneo quanto à densidade e à diversidade de árvores que sombreiam o cacaueiro, muito distinto de um monocultivo.

As equações tiveram o coeficiente de determinação aumentado com a inclusão da variável MFE no modelo de regressão (Tabela 5), fato também observado por Van den Berg e Perkins (2004). Porém, o acréscimo de $\mathrm{R}^{2}$ foi pequeno (na ordem de $3 \%$ ), não justificando sua utilização em rotina, uma vez que não é prático para o cacauicultor preparar a amostra para calcular a MFE. Os coeficientes de determinação das equações também tiveram pouca alteração com a inclusão da AF nos modelos (Tabela 5).

TABELA 1 - Caracterização climática das zonas úmida e úmida a subúmida do sul da Bahia (SEI, 2007).

\begin{tabular}{|c|c|c|c|c|}
\hline Zona climática & $\begin{array}{c}\text { Temp. Mín } \\
\left({ }^{\circ} \mathrm{C}\right)\end{array}$ & $\begin{array}{c}\text { Temp. Média } \\
\left({ }^{\circ} \mathrm{C}\right)\end{array}$ & Temp. Máx $\left({ }^{\circ} \mathrm{C}\right)$ & Amplitude Térmica $\left({ }^{\circ} \mathrm{C}\right)$ \\
\hline Úmido & 14,4 a 22,5 & 18,4 a 25,3 & 24,3 a 31,2 & 4,9 а 13,5 \\
\hline Úmido a subúmido & 15,3 a 22,4 & 19,4 a 24,6 & 25,4 a 32,2 & 5,0 a 15,5 \\
\hline Zona climática & $\begin{array}{l}\text { Precipitação Média } \\
\text { (mm) }\end{array}$ & \multicolumn{2}{|c|}{ Déficit Hídrico (mm) } & $\begin{array}{c}\text { Excedente Hídrico } \\
(\mathrm{mm})\end{array}$ \\
\hline Úmido & $>2000$ & \multicolumn{2}{|c|}{0 a 345} & 200 a 1409 \\
\hline Úmido a subúmido & \multicolumn{2}{|c|}{1100 a 2000} & 3 а 426 & 22 a 424 \\
\hline
\end{tabular}

TABELA 2 - Municípios do sul da Bahia onde estão localizadas as propriedades rurais selecionadas para este estudo.

\begin{tabular}{lccc}
\hline Municípios (Zona Úmida) & Propriedades & Municípios (Zona Semiúmida) Propriedades \\
\hline Arataca & 1 & Barra do Rocha & 1 \\
Camacan & 1 & Ibirataia & 4 \\
Ibirapitanga & 1 & Itagi & 1 \\
Igrapiúna & 1 & Itagibá & 2 \\
Itabuna & 1 & Ipiaú & 1 \\
Maraú & 1 & Jequié* & 1 \\
Nova Ibiá & 1 & & \\
Piraí do Norte & 1 & & \\
Santa Luzia & 1 & & \\
Uruçuca & 1 & & \\
\hline
\end{tabular}

* A área do município de Jequié localiza- se em três zonas: úmida a subúmida, subúmida a seca e semiárida (SEI, 2007). Neste município, a coleta foi realizada em zona úmida a subúmida, onde se localizam as lavouras de cacau. 
TABELA 3 - Média e coeficiente de variação (CV) do teor e do conteúdo foliar e N, do índice SPAD, da massa foliar específica (MFE) e da área foliar (AF) de folhas diagnóstico de cacaueiros, clone PH16, em zona úmida e semiúmida do sul da Bahia.

\begin{tabular}{ccccccc}
\hline & \multicolumn{2}{c}{ Dois Ambientes } & \multicolumn{2}{c}{ Zona úmida } & \multicolumn{2}{c}{ Zona semiúmida } \\
\hline & Média & CV $(\%)$ & Média & CV $(\%)$ & Média & CV (\%) \\
\cline { 2 - 7 } Teor de N $\left(\mathrm{g} \mathrm{kg}^{-1}\right)$ & 21,30 & 16,9 & 22,00 & 18,2 & 20,50 & 15,0 \\
Conteúdo de N (mg) & 27,22 & 23,1 & 30,47 & 19,3 & 24,00 & 20,2 \\
SPAD & 52,25 & 16,0 & 52,57 & 18,3 & 51,94 & 13,4 \\
MFE $\left(\mathrm{g} \mathrm{m}^{-2}\right)$ & 82,17 & 27,5 & 87,55 & 24,2 & 76,78 & 29,8 \\
AF $\left(\mathrm{cm}^{2}\right)$ & 159,41 & 20,9 & 158,59 & 21,0 & 160,24 & 21,0 \\
\hline
\end{tabular}

TABELA 4 - Coeficientes de correlação linear de Pearson entre teor e conteúdo de N, índice SPAD, massa foliar específica (MFE) e área foliar (AF) de folhas diagnóstico de cacaueiros, clone PH16, em zona úmida e semiúmida do sul da Bahia.

\begin{tabular}{|c|c|c|c|c|}
\hline & \multicolumn{4}{|c|}{ Dois ambientes } \\
\hline & Conteúdo de $\mathrm{N}$ & SPAD & $\begin{array}{l}\text { MFE } \\
\text { MFE }\end{array}$ & $\mathrm{AF}$ \\
\hline Teor de N & $0,501^{*}$ & $0,737 * *$ & $-0,486^{* *}$ & $0,498^{*}$ \\
\hline Conteúdo de $\mathrm{N}$ & & $0,245^{\mathrm{ns}}$ & $0,242^{\mathrm{ns}}$ & $0,215^{\text {ns }}$ \\
\hline SPAD & & & $-0,573^{* *}$ & $0,622 * *$ \\
\hline \multirow[t]{2}{*}{ MFE } & & & & $-0,760 * *$ \\
\hline & \multicolumn{4}{|c|}{ Zona úmida } \\
\hline Teor de $\mathrm{N}$ & $0,384 *$ & $0,747 * *$ & $-0,648 * *$ & $0,546 * *$ \\
\hline Conteúdo de N & & $0,190^{\text {ns }}$ & $0,082^{\text {ns }}$ & $0,325^{*}$ \\
\hline SPAD & & & $-0,688 * *$ & $0,659 * *$ \\
\hline \multirow[t]{2}{*}{ MFE } & & & & $-0,766^{* *}$ \\
\hline & \multicolumn{4}{|c|}{ Zona semiúmida } \\
\hline Teor de N & $0,583^{* *}$ & $0,745^{* *}$ & $-0,484 * *$ & $0,487 *$ \\
\hline Conteúdo de N & & $0,394 *$ & $0,210^{\mathrm{ns}}$ & $0,201^{\mathrm{ns}}$ \\
\hline SPAD & & & $-0,514 * *$ & $0,595 * *$ \\
\hline MFE & & & & $0,787 * *$ \\
\hline
\end{tabular}

**, *: Significativo a $1 \%$ e $5 \%$ de probabilidade de erro,pelo teste $t$.

TABELA 5 - Teste de identidade de modelos (valor F) e equações de regressão linear que estimam o teor de N foliar de cacaueiros, clone PH16, em função do índice SPAD, área foliar (AF, em $\mathrm{cm}^{2}$ ) e massa foliar específica (MFE, em $\mathrm{g} \mathrm{m}^{-2}$ ), na zona úmida (ZU) e semiúmida (ZSU) do sul da Bahia.

\begin{tabular}{|c|c|c|c|c|c|}
\hline Zonas climáticas & Equação de regressão & $\mathrm{R}^{2}$ & $\begin{array}{c}\text { QM } \\
\text { (diferença) }\end{array}$ & QM (resíduo) & $\mathrm{F}$ \\
\hline$\overline{Z U}+\mathrm{ZSU}$ & $\hat{\mathrm{y}}=4,717+0,317 * *$ SPAD & 0,54 & 10,89 & 8,55 & $1,27^{\text {ns }}$ \\
\hline ZU & $\hat{y}=5,784+0,309 * *$ SPAD & 0,56 & & & \\
\hline ZSU & $\hat{y}=3,736+0,324 * *$ SPAD & 0,56 & & & \\
\hline $\mathrm{ZU}+\mathrm{ZSU}$ & $\hat{y}=4,506+0,300 \mathrm{SPAD}^{* *}+0,007 * \mathrm{AF}$ & 0,55 & 3,38 & 8,89 & $0,38^{\text {ns }}$ \\
\hline $\mathrm{ZU}$ & $\hat{y}=5,342+0,283 \mathrm{SPAD}^{* *}+0,011 * \mathrm{AF}$ & 0,56 & & & \\
\hline ZSU & $\hat{y}=3,668+0,306 \mathrm{SPAD}^{* *}+0,006^{*} \mathrm{AF}$ & 0,56 & & & \\
\hline $\mathrm{ZU}+\mathrm{ZSU}$ & $\hat{y}=7,191+0,294^{*} * \mathrm{SPAD}-0,015^{*} \mathrm{MFE}$ & 0,57 & 2,96 & 8,56 & $0,34^{\text {ns }}$ \\
\hline ZU & $\hat{y}=13,767+0,237 * *$ SPAD $-0,048 *$ MFE & 0,60 & & & \\
\hline ZSU & $\hat{y}=6,734+0,293 * *$ SPAD $-0,018 *$ MFE & 0,59 & & & \\
\hline \multicolumn{6}{|c|}{$\begin{array}{l}\text { QM: quadrado médio. } \\
* * \text { Significativo a } 1 \% \text { de probabilidade, pelo teste } \mathrm{F} \text {. } \\
\text { ns: não significativo, pelo teste } \mathrm{F} \text {. }\end{array}$} \\
\hline
\end{tabular}




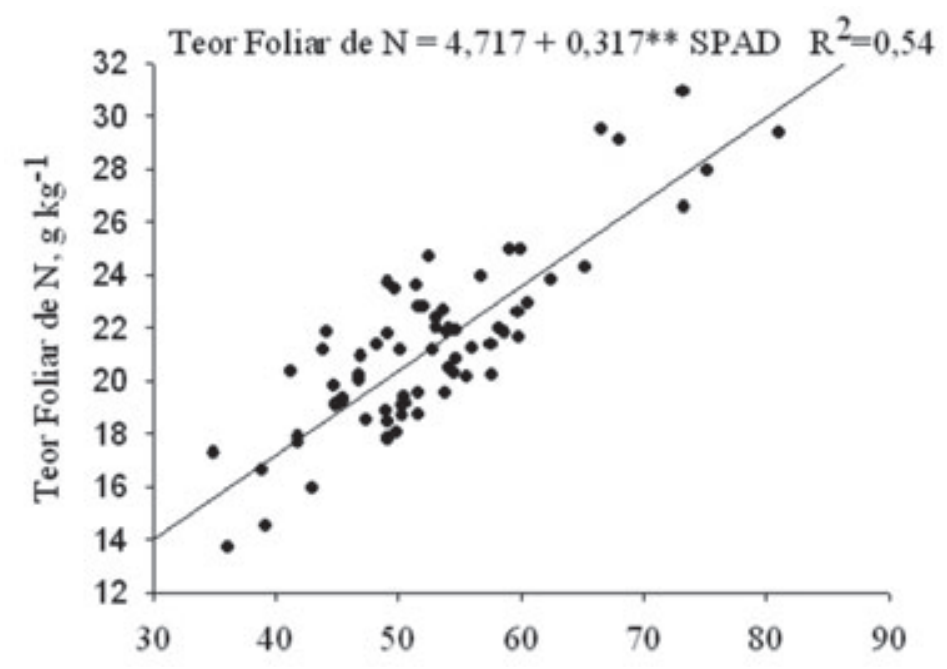

FIGURA 1 - Relação entre índice SPAD e teor foliar de N de cacaueiros, clone PH16, no sul da Bahia, nos dois ambientes conjuntamente (zonas úmida e semiúmida).

** Significativo a $1 \%$ de probabilidade, pelo teste F.

\section{CONCLUSÕES}

1- O SPAD apresenta potencial para ser utilizado para estimar o teor foliar de $\mathrm{N}$ em cacaueiros, em sistema agrossilvicultural, nas regiões climáticas estudadas.

2- O índice SPAD também se correlaciona significativamente à área foliar e à massa foliar específica das plantas de cacau.

\section{REFERÊNCIAS}

ALMEIDA, A. A. F.; VALLE, R. R. Ecophysiology of the cacao tree. Brazilian Journal of Plant Physiology, Londrina, v. 19, n. 4, p. 425-448, 2007.

ARGENTA, G.; SILVA, P. R. F.; BORTOLINI, C. G.; FORSTHOFER, E. L.; STRIEDER, M. L. Relação da leitura do clorofilômetro com os teores de clorofila extraível e de nitrogênio na folha de milho. Revista Brasileira de Fisiologia Vegetal, Lavras, v. 13, n. 2, p. 158-167, 2001.

CABANGON, R. J.; CASTILLO, E. G.; TUONG, T. P. Chlorophyll meter-based nitrogen management of rice grown under alternate wetting and drying irrigation. Field Crop Research, Amsterdam, v. 121, n. 1, p. 136-146, 2011.
CANTARUTTI, R. B.; BARROS, N. F.; MARTINEZ, H. E. P.; NOVAIS, R. F. Avaliação da fertilidade do solo e recomendação de fertilizantes. In: NOVAIS et al. (Ed.). Fertilidade do solo. Viçosa: Sociedade Brasileira de Ciência do Solo, 2007. p. 769-850.

CHEPOTE, R. E.; SODRÉ, G. A.; REIS, E. L.; PACHECO, R. G.; MARROCOS, P. C. L.; SERÔDIO, M. H. C. F.; VALLE, R. R. Recomendações de corretivos e fertilizantes na cultura do cacaueiro no Sul da Bahia $-2^{\mathrm{a}}$ aproximação. Ilhéus: CEPLAC/ CEPEC, 2005. 36p.

COSTA, K. A. P.; FAQUIN, V.; OLIVEIRA, I. P.; ARAÚJO, J. L.; RODRIGUES, R. B. Doses e fontes de nitrogênio em pastagem de capim-marandu. II Nutrição nitrogenada da planta. Revista Brasileira de Ciência do Solo, Viçosa, MG, v. 32, n. 4, p.16011607, 2008.

EMBRAPA. Manual de análises químicas de solos, plantas e fertilizantes. 2. ed. Brasília: Embrapa Informação Tecnológica, 2009. 627p.

ENGEL, V. L.; POGGIANI, F. Estudo da concentração de clorofila nas folhas e seu espectro de absorção de luz em função do sombreamento em mudas de quatro espécies florestais nativas. Revista Brasileira de Fisiologia Vegetal, Lavras, v. 3, n. 1, p. 39-45, 1991. 
EVANS, J. R. Photosynthesis and nitrogen relationships in leaves of C3 plants. Oecologia, Berlin, v. 78, p. 9-19, 1989.

GIANELLO, C.; CAMARGO, F. A. O.; REICHMANN, E.; TEDESCO, M. J. Avaliação da disponibilidade do nitrogênio do solo estimada por métodos químicos. Revista Brasileira de Ciência do Solo, Viçosa, MG, v. 24, p. 93-101, 2000.

GODOY, L. J. G.; VILLAS BÔAS, R. L.; BULL, L. T. Utilização da medida do clorofilômetro no manejo da adubação nitrogenada em plantas de pimentão. Revista Brasileira de Ciência do Solo, Viçosa, MG, v. 27, n. 6, p. 1.049-1.056, 2003.

GODOY, L. J. G.; SANTOS, T. S.; VILLAS BÔAS, R. L.; LEITE JÚNIOR, J. B. Índice relativo de clorofila e o estado nutricional em nitrogênio durante o ciclo do cafeeiro fertirrigado. Revista Brasileira de Ciência do Solo, Viçosa, MG, v. 32, n. 1, p. 217 226, 2008.

LAVRES JÚNIOR, J.; MONTEIRO, F. A. Diagnose nutricional de nitrogênio no capim-aruana em condições controladas. Revista Brasileira de Ciência do Solo, Viçosa, MG, v. 30, n. 5, p. 829-837, 2006.

MAJEROWICZ, N. Fotossíntese. In: KERBAUY, G. B. (Ed.). Fisiologia vegetal. Rio de Janeiro: Editora Guanabara, 2004. p. 114-178.

MAJEROWICZ, N.; PERES, L. E. Fotomorfogênese em Plantas. In: KERBAUY, G. B. (Ed.). Fisiologia vegetal. Rio de Janeiro: Editora Guanabara, 2004. p. 421-438.

MALAVOLTA, E. Manual de calagem e adubação das principais culturas. São Paulo: Agronômica Ceres, 1987. 497p.

MANDARINO, E. P.; GOMES, A. R. S. Produtividade do cacaueiro (Theobroma cacao $L$.) cultivado em blocos monoclonais, no sul da Bahia, Brasil. Ilhéus: CEPLAC/CEPEC, 2009. 32p. (Boletim Técnico, 197).

MARENCO, R. A.; ANTEZANA-VERA, S. A.; NASCIMENTO, H. C. S. Relationship between specific leaf area, leaf thickness, leaf water content and SPAD-502 readings in six Amazonian tree species. Photosynthetica, Prague, v. 47, n. 2, p. 184190, 2009.
NACIF, P. G. S. Ambientes naturais da bacia hidrográfica do Rio Cachoeira, com ênfase nos domínios pedológiocos. 2000. 132f. Tese (Doutorado em Ciência do Solo)-Universidade Federal de Viçosa, Viçosa, 2000.

PETERSON, T. A.; BLACKMER, T. M.; FRANCIS, D. D.; SCHEPPERS, J. S. Using a chlorophyll meter to improve $\mathbf{N}$ management. Nebraska:Cooperative Extension, Institute of Agriculture and Natural Resources, University of Nebraska, 1993. 4p.

REGAZZI, A. J. Teste para verificar a identidade de modelos de regressão. Pesquisa Agropecuária Brasileira, Brasília, v. 31, n. 1, p. 1-17, 1996.

REIS, A. R.; FURLANI JÚNIOR, E.; BUZETTI S.; ANDREOTTI, M. Diagnóstico da exigência do cafeeiro em nitrogênio pela utilização do medidor portátil de clorofila. Bragantia, Campinas, v. 65, n. 1, p. 163-171, 2006.

SANTANA, M. B. M.; IGUE, K. Composição química das folhas do cacaueiro em função da idade $\mathrm{e}$ da época do ano. Revista Theobroma, Itabuna, v. 9, p. 63-76, 1979.

SANTIAGO, A. R.; BARROSO, D. G.; MENDONÇA, A. V. R.; CAMPOSTRINI, E.; CARNEIRO, J. G. A.; DETMANN, E. Monocultivo de eucalipto e consórcio com sesbânia: crescimento inicial em cavas de extração de argila. Revista Árvore, Viçosa, MG, v. 33, n. 1, p. 67-79, 2009.

SEAGRI - Secretaria de Agricultura, Irrigação e Reforma Agrária do Estado da Bahia. Cacau no Brasil e no mundo: relatório 41/10. 2011. Disponível em: <http://www.seagri.ba.gov.br/cacauth/ cacauth11012011.pdf > . Acesso em: 20 jan. 2011.

SEI - Superintendência de estudos econômicos e sociais da Bahia. Tipologia climática - segundo Thornthwaite - do Estado da Bahia, 2007. (Informações Geoambientais). Disponível em: $<$ http:// www.sei.ba.gov.br/site/geoambientais/cartogramas/ pdf/carto tip clim.pdf> Acesso em: 21 jan. 2011.

TORRES NETTO, A.; CAMPOSTRINI, E.; OLIVEIRA, J. G.; YAMANISHI, O. K. Portable chlorophyll meter for the quantification of photosynthetic pigments, nitrogen and the possible use for assessment of the photochemical process in Carica papaya L. Brazilian Journal of Plant Physiology, Londrina, v. 14, n. 3, p. 203-210, 2002. 
TORRES NETTO, A.; CAMPOSTRINI, E.; OLIVEIRA, J. G.; BRESSAN-SMITH, R. E. Photosynthetic pigments, nitrogen, chlorophyll a fluorescence and SPAD-502 readings in coffee leaves. Scientific Horticulture, Kent, v. 104, p. 199-209, 2005.

VAN DEN BERG, A.K.; PERKINS, T. D. Evaluation of a portable chlorophyll meter to estimate chlorophyll and nitrogen contents in sugar maple (Acer saccharum Marsh.) leaves. Forest Ecology and Management, Amsterdam, v. 200, p. 113-117, 2004.
WANG, D.; MAUGHAN, M. W.; SUN, J.; FENG, X.; MIGUEZ, F.; LEE, D.; DIETZE, M. C. Impact of nitrogen allocation on growth and photosynthesis of Miscanthus (Miscanthus giganteus). Global Change Biology Bioennergy. Disponível em: $<$ http://onlinelibrary.wiley.com/doi/10.1111/j.17571707.2012.01167.x/full>. Acesso em: 20 jun. 2012. DOI: $10.1111 / j .1757-1707.2012 .01167 . x$ 